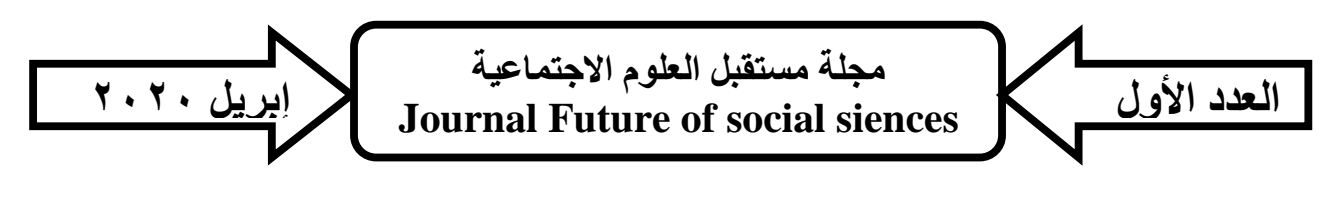

\title{
إستخدام الألعاب التعليمية الإليكترونية ودورها في تنمية المهارات التربوية واللغوية
}

\author{
د/ شيسماء سلطان هممد \\ مدرس لغة عربية
}

$$
r^{r} \cdot r \cdot
$$




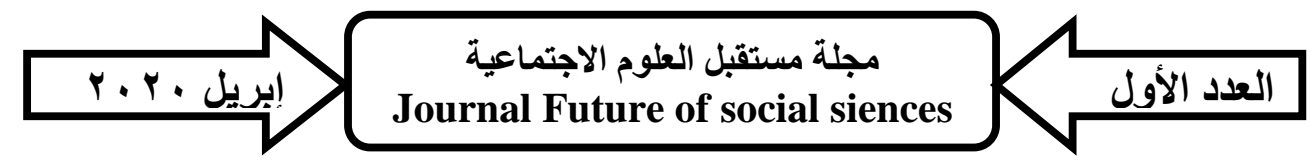




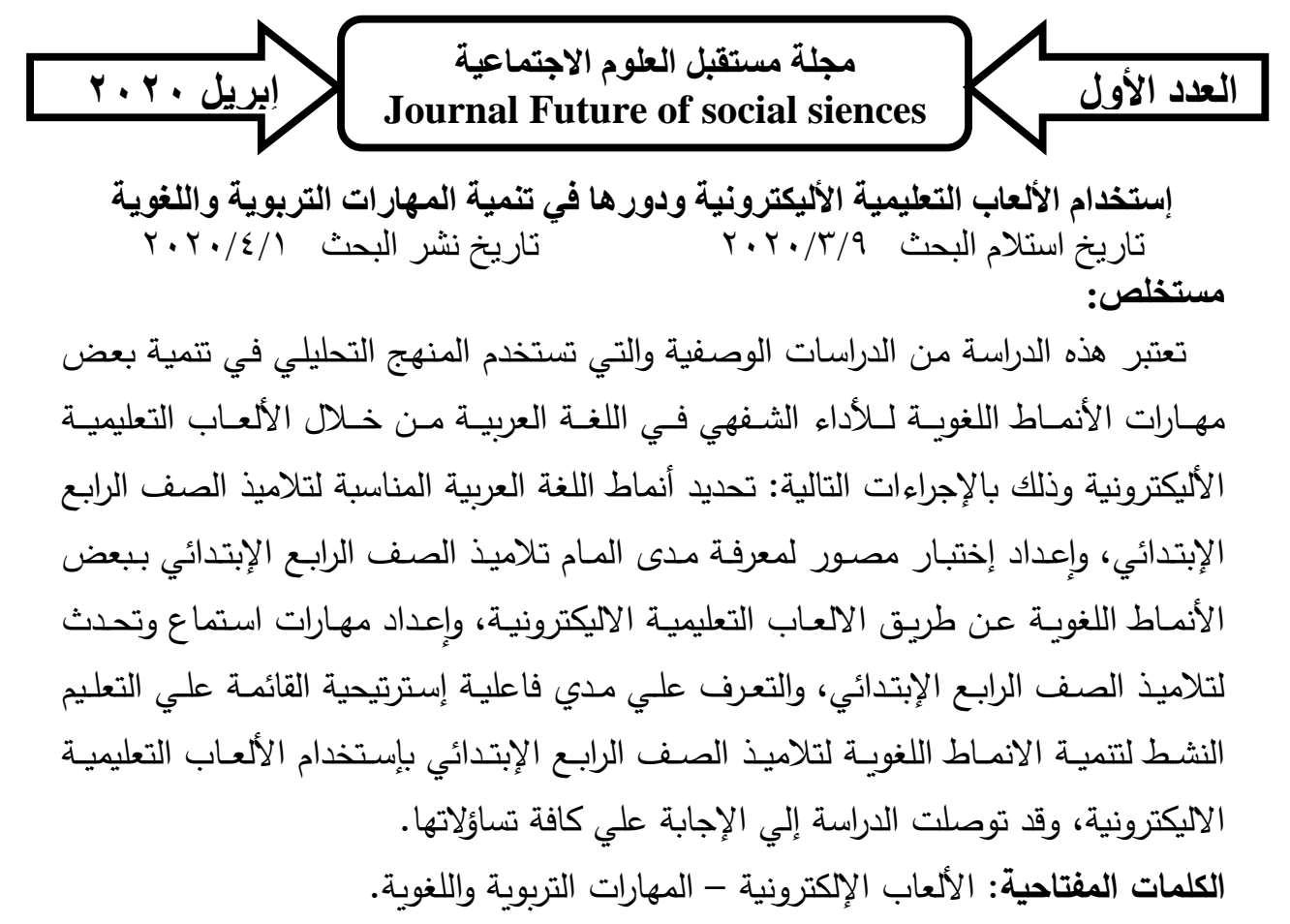

Abstract:

This study is considered one of the descriptive studies that uses the analytical method to develop some of the linguistic patterns of oral performance in the Arabic language through electronic educational games, with the following procedures: Determining the appropriate Arabic language patterns for students of the fourth grade of primary, and preparing a pictorial test to find out the extent of knowledge for fourth grade students With some linguistic patterns through electronic educational games, preparing listening and speaking skills for fourthgrade pupils of primary school, and identifying the extent of the effectiveness of restoration based on active education to develop the linguistic patterns of fourth-grade pupils using electronic educational games, and the study reached an answer to all its questions.

Key words: electronic games - educational and language skills. 
إن إعتماد المتخصصين علي الألعاب التعليمية الأليكترونية علي دمـج عملية التعليم

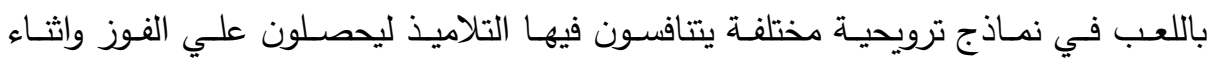

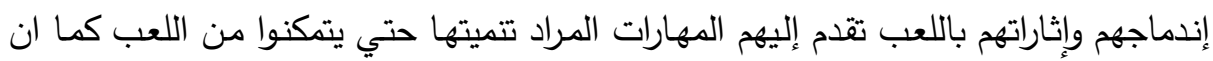

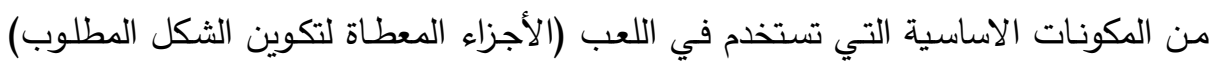

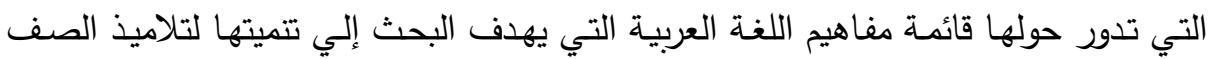
الرابع الإبتدائي وبالتالي ان إستراتيجيات التعليم بالمساعدة الاليكترونيـة أحد الإستراتيجيات

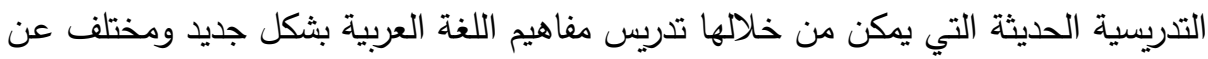

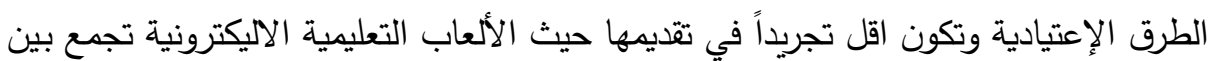
الجانب الترفيهي والجانب التعليمي في وقت واحد مما يساعد المتعلم علي تعليم مهارات اللغة العربية بسهولة ويكون لها تأثير علي باقي بنيته التعليمية.

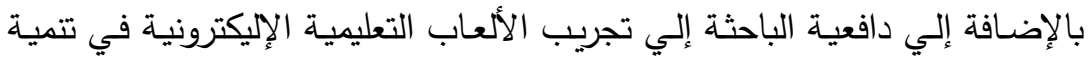

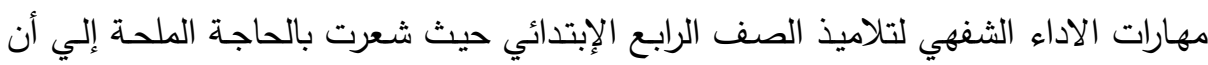

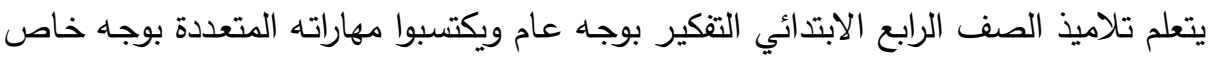

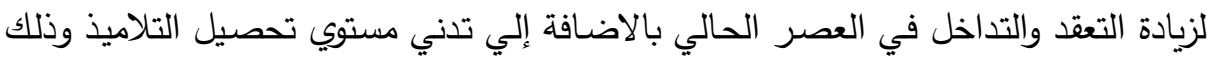

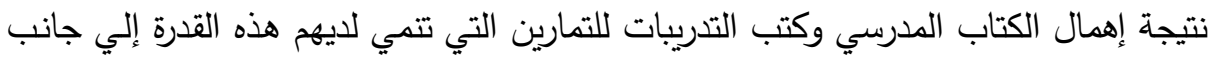
عدم إهتمام المعلمين بالطرائق والأساليب الحديثة التي يمكن أن تتمي لديهم القدرة علي التفكير المنطقي.

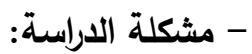
تتمثل مشكلة الدراسة في ضعف القدرة علي التفكير بشكل عام بشكل خاص لتلاميذ المرحلة الإبتدائية إلي جانب ذلك صعوبة إتقان وفهم العديد من التلاميذ لمفاهيم اللغة العربية

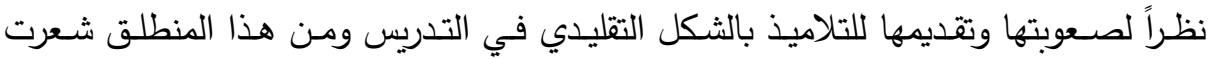
الباحثة بأهميـة تجريب الألعـاب التعليميـة الكمبيوتريـة في تنميـة التعليم النثط في في الانهـاط اللغوية لتلاميذ الصف الرابع الإبتدائي بإستخدام الألعاب التعليمية الاليكترونية التي يتضمنها

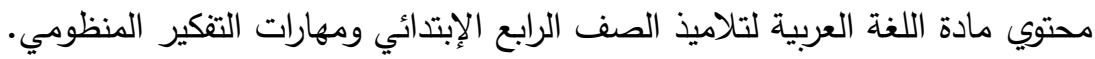

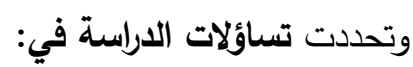
1- ما أنماط اللغة العربية المناسبة لتلاميذ الصف التهات الرابع الإبتدائي؟ 


\section{|ابريل ·.r. مجلة مستقبل العلوم الاجتماعية}

r- مـا مهارات الأداء الثفهي المناسبة لتلاميذ الصف الرابع الإبتدائي بإستخدام الالعاب

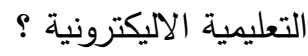
r- ما المتوافر من مهارات الأداء الثفهي المناسبة لتلاميذ الصف الرابع الإبتدائي بإستخدام الألعاب التعليمية الاليكترونية ؟ ع- ما الإستراتيحية المقترحة القائمة علي التعليم النثط لتتمية الانماط اللغوية لتلاميذ الصف الرابع الإبتدائي بإستخدام الألعاب التعليمية الاليكترونية ؟

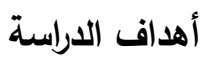
هدفت الدراسة إلي تتمية بعض مهارات الأنماط اللغوية للأداء الثفهي في اللغة العربية من خلال الألعاب التعليمية الأليكترونية وذلك بالإجراء ات التهات التالية: 1- تحديد أنماط اللغة العربية المناسبة لتلاميذ الصف الريكرونة الرابع الإبتدائي.

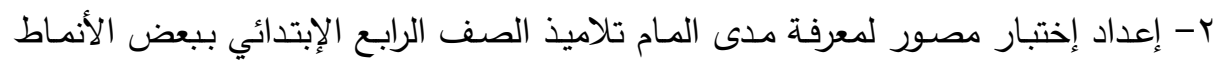
اللغوية عن طريق الالعاب التعليمية الاليكترونية. r- إعداد مهارات استماع وتحدث لتلاميذ الصف الرابع الإبع الإبتدائي.

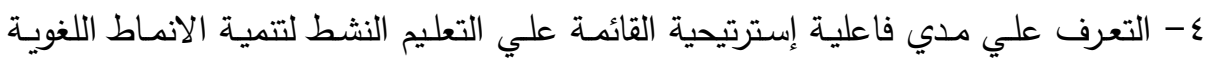
لتلاميذ الصف الرابع الإبتدائي بإستخدام الألعاب التعليمية الاليكترونية. أهمية الدراسة تكمن أهمية الاراسة في العديد من الأمور من أهمها:-

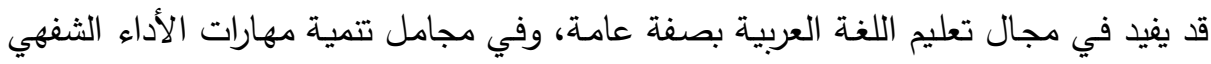

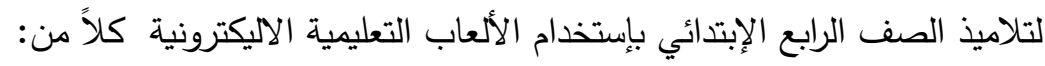

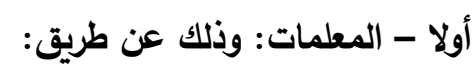
1- تعرف المهارات المناسبة لتلاميذ الصف الرفئ الرابع الإبتدائي في اللغـة العربية في الأداء

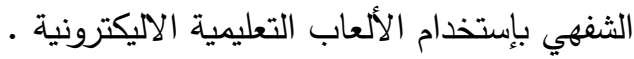

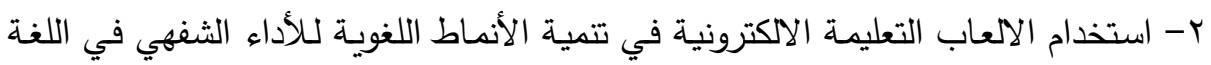
العربية لتلاميذ الصف الرابع الإبتدائي

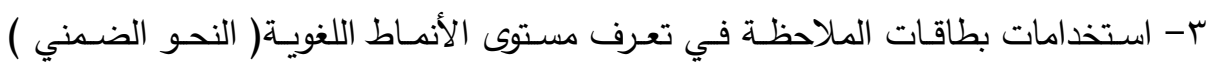
لتلاميذ الصف الرابع الإبتدائي لما له من أثر جيد في التحدث بلغة فئة فصحي صحيحة. 


\section{إبريل ·.r. مجلة مستقبل العلوم الاجتماعية ثانيا- واضعي مناهج الصف الرابع الإبتدائي:} عن طريق تعريفه بالإستراتيجية المقترحة في تتمية الأداء الثفهي، ومعايير بنائها في تطوير الإيتاني

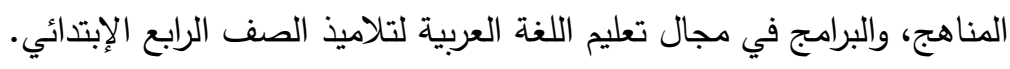

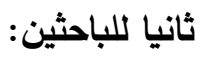
تود الباحثة أن تقدم هذه الدراسة للباحثين أفكارا يستطيعون من خلالها البدء في التنكير في

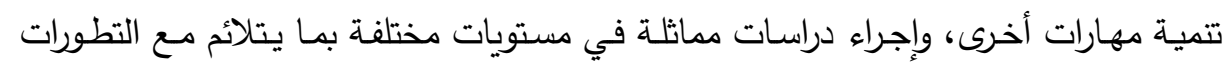
التكنولوجية الحديثة. مصطلحات الاراسة: مفهوم الألعاب التعليمية الإليكترونية:- مدات التهاب

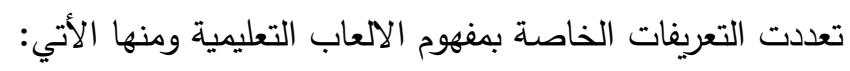

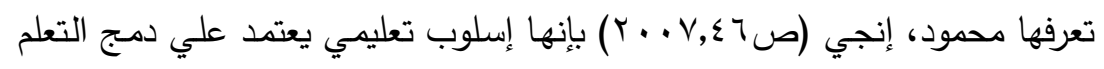

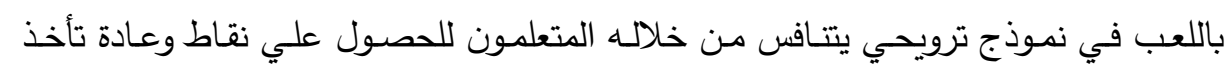

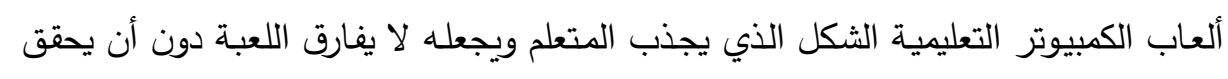

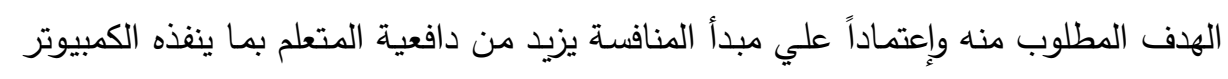

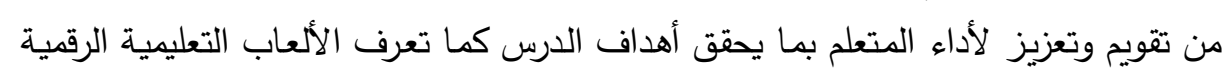

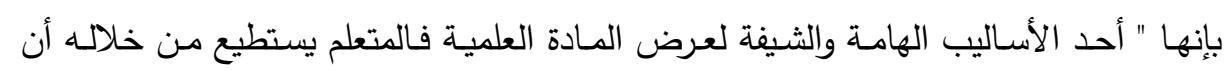

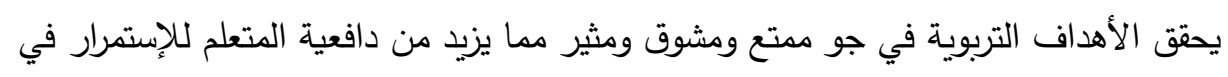

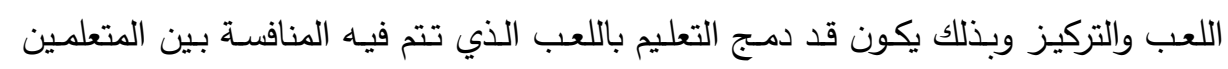

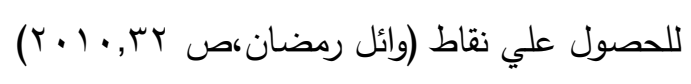

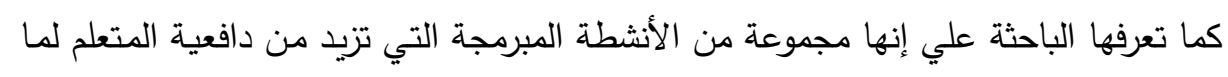

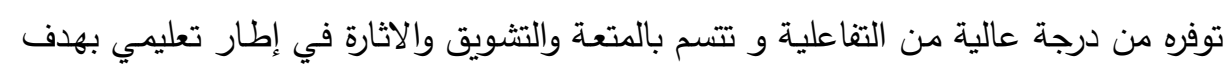

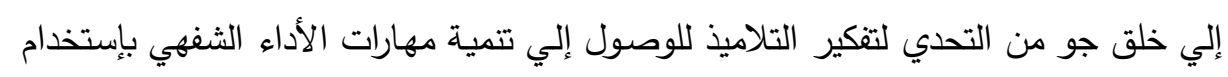

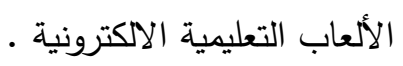

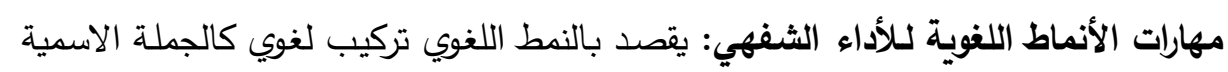

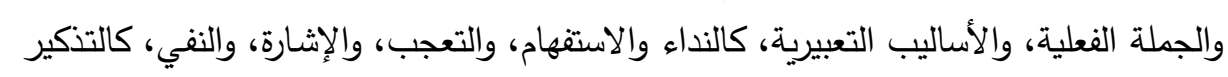

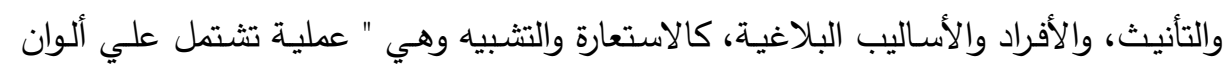
النشاط والإجراءات، التي ينظمها المعلم في موقف معين أو عدد من المواقف، معها التلاميذ الأيذ 


\section{Y.r. إبريل}

مجلة مستقبل العلوم الاجتماعية Journal Future of social siences

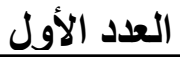

فيتمكن من خلال هذا التفاعل من أن ينطق النمط اللغوي ويستخدمه استخداما وظيفيا، بالقدر

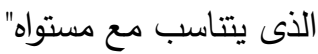

وتقصد الباحثة بانها مجموعة من التراكيب اللغويـة، والأسـاليب التعبيرية، التي يستخدمها

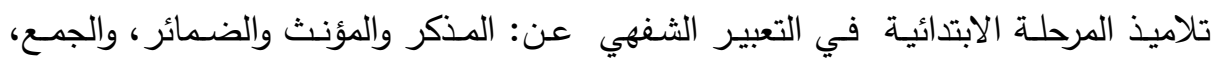
وظرف الزمان والمكان، دون تعريف للمصطلح اللغوي نحوا أو بلاغة". الدارات السابقة المتعلقة بالاراسة الحالية داسلة لاي وأخرون (lai,2008)هدفت الدراسة إلي معرفة أثر تدريب الأطفال في بالئه

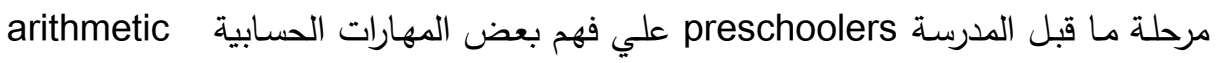

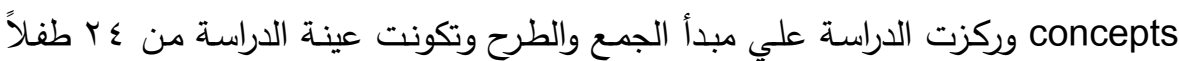

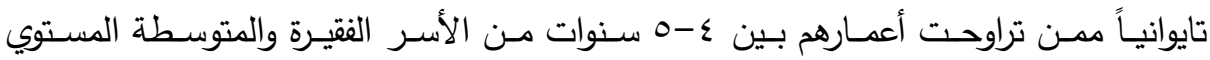

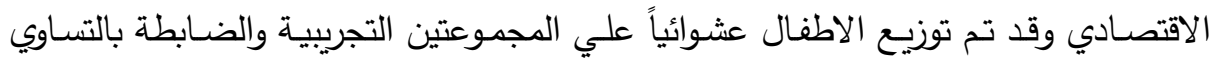

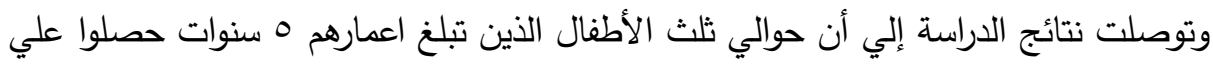

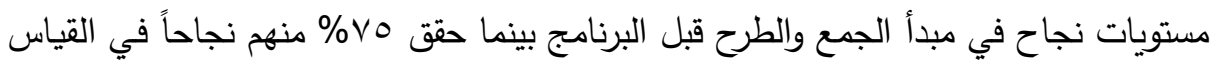

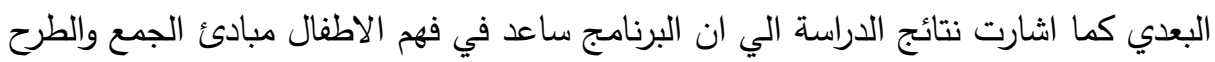
بغض النظر علي المستوي الاقتصادي.

دراسة سيمون ( Simon2014) هدفت الدراسة إلي معرفة أثربرنامج تدريبي في تتمية بعض المهارات الحسابية للأطفال ذوي صعوبات التعلم حيث ركزت الدراسة علي مشكلات

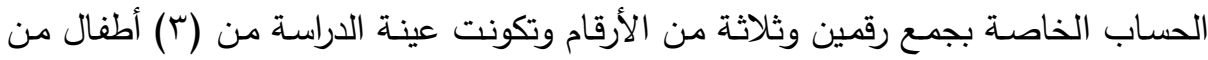
ذوي التعلم وقبل البرنامج التدريسي كان الأطفال يعتمدون علي إستراتيجيات العد بالأعتماد

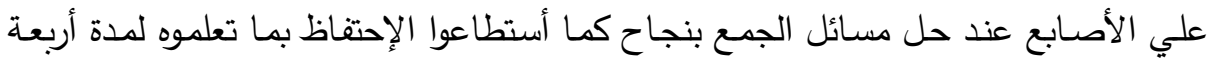
أشهر ونصف بعد الإنتهاء من البرنامج. دراسـة فيلتي ( vilette,2016) هدفت الدراسة إلي التوصل إلي نموذج مقترح قائم علي تتمية قدرة الأطفال علي الجمع والطرح من غير عمليات حسابية وحاول الباحث إختبار

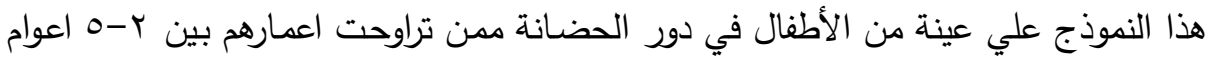
والذين قام الباحث بتدريهم علي مبادئ الجمع والطرح بإستخدام إحداث ومواقف معقولة وغير

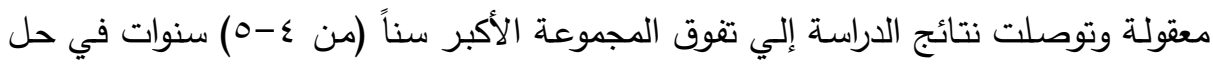
مشكلات قلب عملية الجمع والطرح ثم قام الباحث بدراسة تتبعية إستخدام فيها برنامج تدريبي 


\section{r.r. إبريل}

مجلة مستقبل العلوم الاجتماعية

Journal Future of social siences

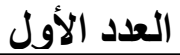

للأطفال في المجموعة الأصغر سناً (r-؛) سنوات والتي قاموا فيها بأداء عمليات تحويل

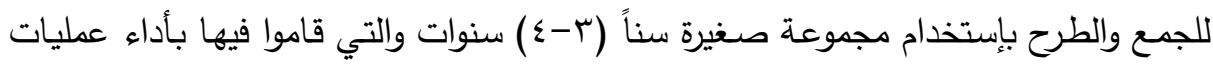

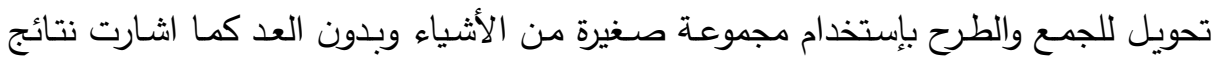

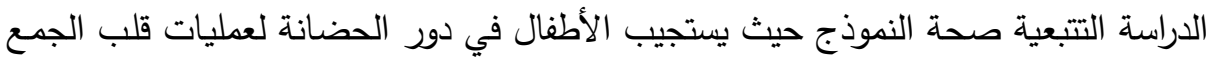
والطرح علي أساس الأشياء لأكثر من الأعداد.

دراسة النعيمي،أحمد محمد حسن 9 بـ ب بعنوان (فاعلية برنامج قائم على البنائية

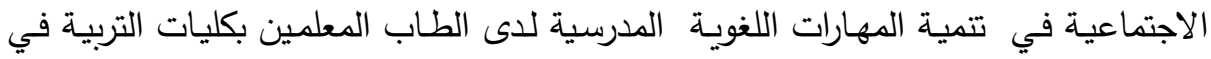
العراق) هدف هذا البحث إلى: تتمية المهارات اللغوية المدرسية لدى الطلاب المعلمين قسم الإله اللغـة العربيـة بكليات التربيـة في العراق، وذلك مـن خـال إعداد برنـامج قائم على البنائيـة

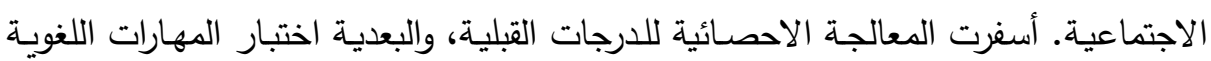

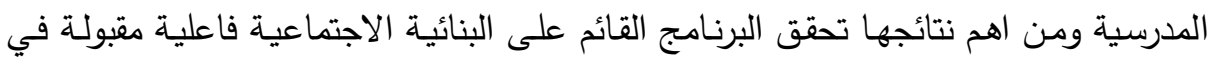
تتمية المهارات اللغوية المدرسية للطلاب المعلمين بقسم اللغة العربية بكليات التربية بالعراق،

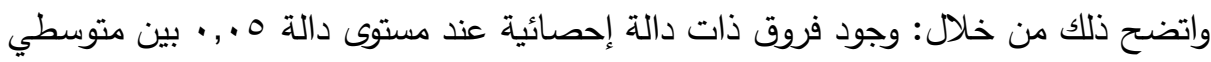

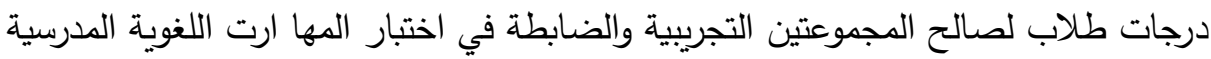
ككل بعدياً طلاب المجموعة التجريبية.

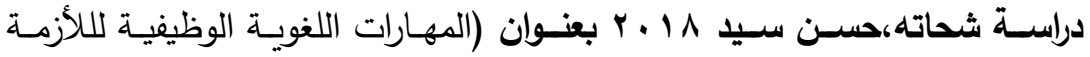

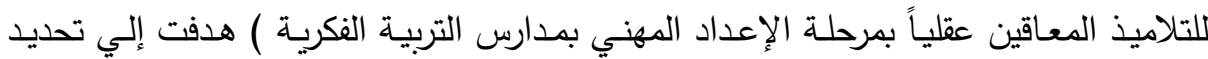

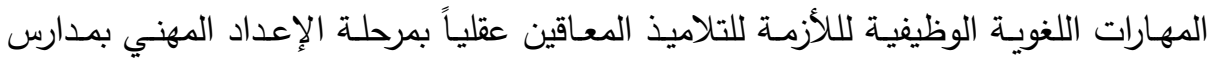

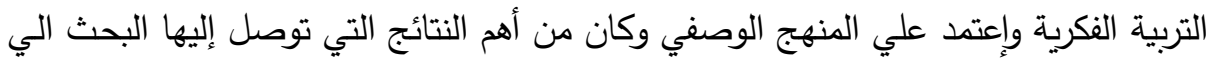

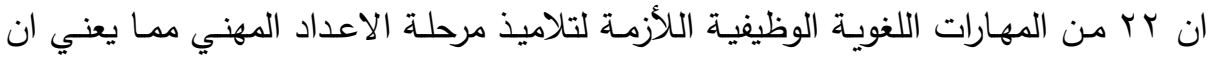
معظم المهارات التي وضعت بالقائمة المبدئية مناسبة لتلك الفئة وقد يغزو الباحث هذه النتيجة

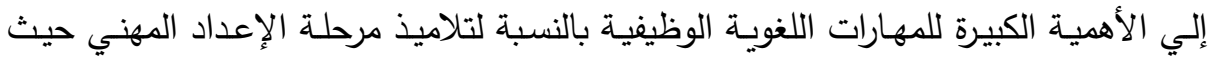

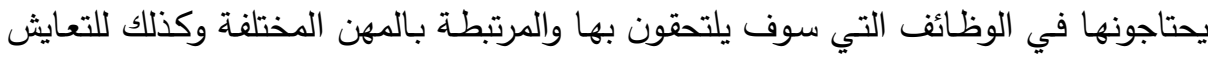
في المجتمع الذي يعيشون فيه. تعقيب علي الداسات السابقة:

إستفادت الباحثة من عرضها لهذه الدراسات في التعرف علي واقع وطبيعة نمط تقديم الألعاب التعليمية الإليكترونية (الفردية - التعاونية ) وكيفية تقديم كل منها للأطفال في لإنيات 
مرحلة الإبتدائية وخاصة تلاميذ الصف الرابع الإبتدائي.وايضاً التعرف علي خطوات تصميم

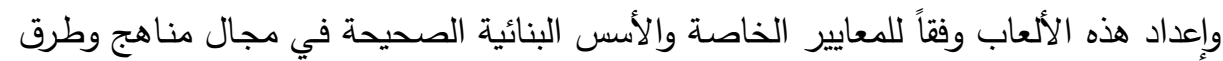
التدريس بإستخدام الألعاب التعليمية الإليكترونية.

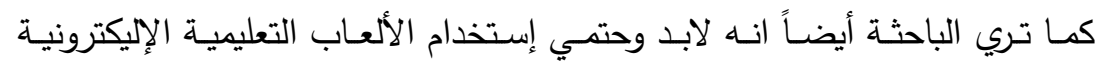

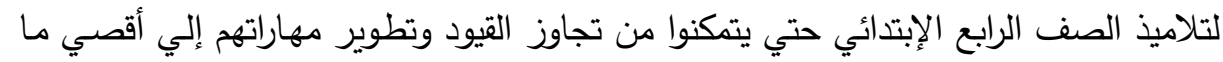

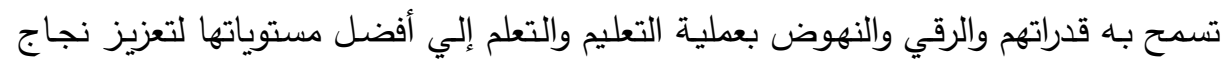

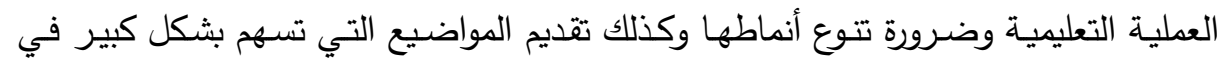

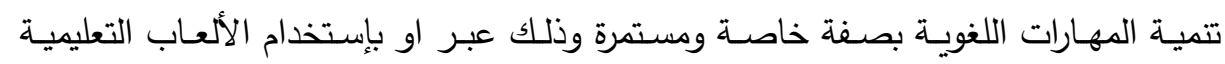

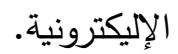

كما أستفادت الباحثة من عرض الأدبيات التربوية والدراسات السابقة في هذا البحث العديد من الجوانب الخاصة ومنها:-

- - إعداد أدوات البحث المتماثلة في إختبار المهارات اللغوية، مقياس الدافعية للتعلم ) - - التعرف علي طبيعة ونمط تقديم الألعاب التعليمية الإليكترونية (الفردية والجماعية)

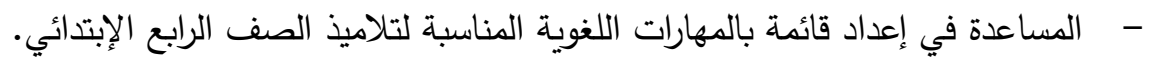

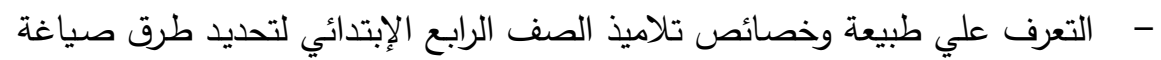
المتوي التي تتاسب مع قدراتهم. - - تعديل الصياغة اللغوية لبعض المعايير مثل عبارة ان يكون المحتوي مناسب لتلاميذ

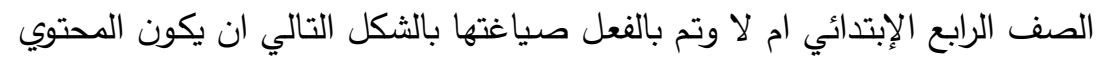
مناسب لمستوي او درجة ذكاء المرحلة العمرية.

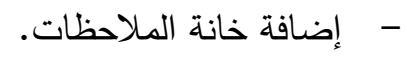
- - اعادة ترتيب بعض المعايير والمؤشرات. - - حذف بعض الكلمات المكررة في صياغة بعض المعايير بدقة وسرعة.

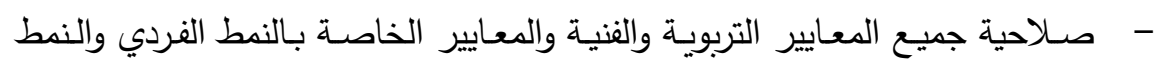

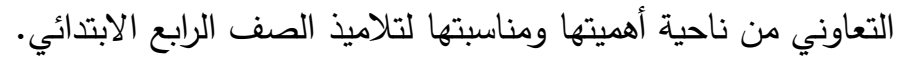

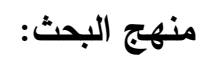
نظراً لطبيعة البحث فإن الباحثة مزجت بين منهحين: 
المنهج الوصفي: وذلك لتحديد مهارات الإستماع والتحدث لتلاميذ الصف الرابع الابتدائي

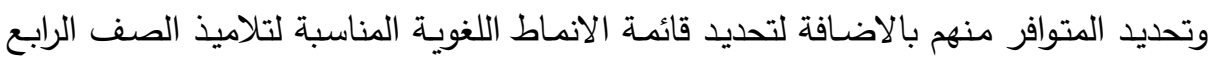

$$
\text { الابتدائي باستخدام الالعاب التعليمية الالكترونية. }
$$

المنهج شبه التجريبي:الذي اعتمد علي اختبار مجموعة بحثية واحدة طبقت عليها الباحثة الإنة

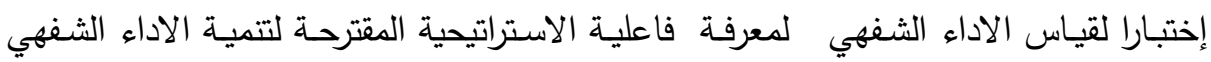
باستخدام الالعاب التعليمية الإكترونية. التصميم شبه التجريبي: نفذت الباحثة تجربة البحث من خلال التصميم التجريبي للمجموعه الواحدة مع تطبيق أختبار مهارا ت التحدث تطبيقيا قبليا وبعدياً.

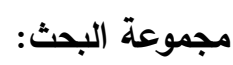

ثلاثون تلميذ وتلميذة من تلاميذ الصف الرابع الإبتدائي، بمديرية التربية والتعليم (حيث تعمل الباحثة بها). حدود البحث:

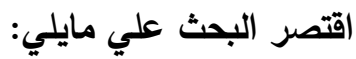
- حدود موضوعية: فاعلية الالعاب التعليمية الالكترونية في تتمية الأنماط اللغوية المناسبة

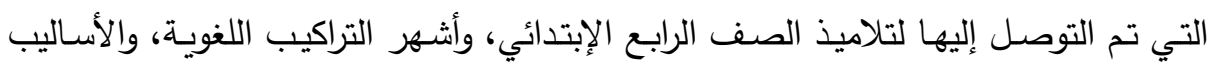

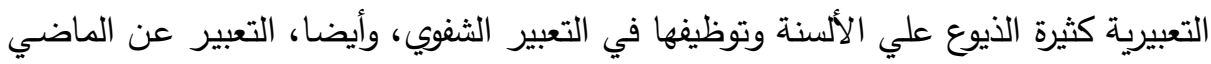

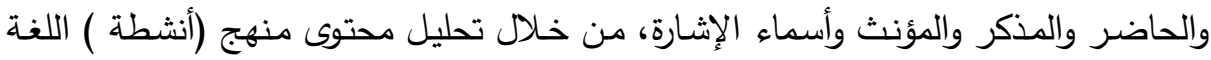
العربية لتلاميذ الصف الرابع الإبتدائي.

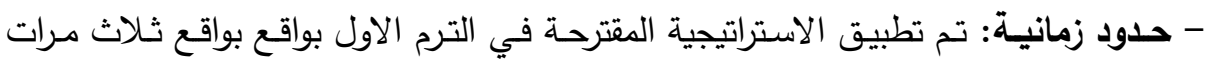

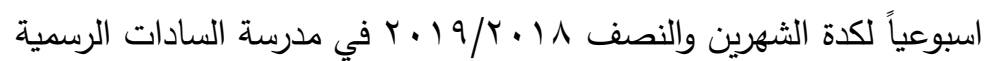
المعالجة الإحصائية إجراءات البحث للإجابة علي السؤال ونصـه: مـا الانمـاط اللغويـة المناسبة لتلاميذ الصف الرابع الإبتدائي، قامت الباحثة بالإجرات التالية: 


\section{r.r. إبريل}

مجلة مستقبل العلوم الاجتماعية

Journal Future of social siences

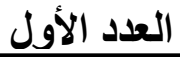

1- الاطلاع علي الدراسات والبحوث السابقة والادبيات المتعلقة بموضوع البحث للوقوف

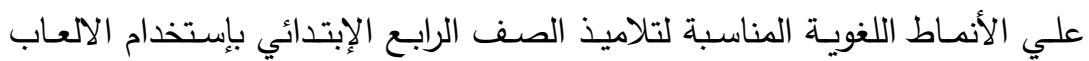

الالكترونية.

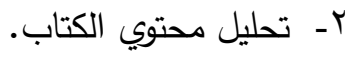

r- اعداد قائمة بالانماط اللغوية المناسة لتلاميذ الصف الكابـ الرابع الإبتدائي.

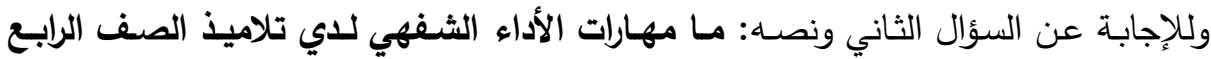

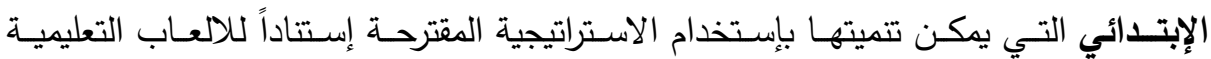

الالكترونية قامت الباحثة بالاجراءات التالية:

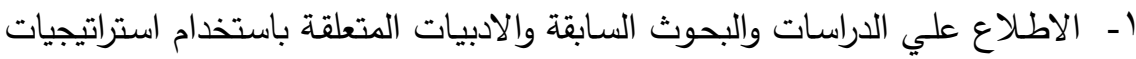

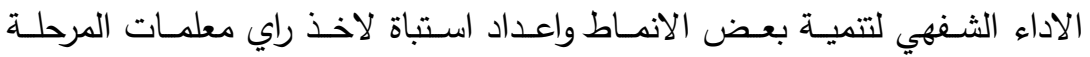

الابتدائية في بعض الانماط اللغوية.

r- الاطلاع علي اهداف كتاب الوزارة والمعايير القومية للمرحلة الإبتدائية.

r- اعداد قائمة المهارات (استماع وتحدث) لتلاميذ الصف الرابع الرابع الإبتدائي.

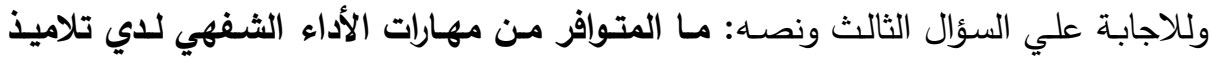

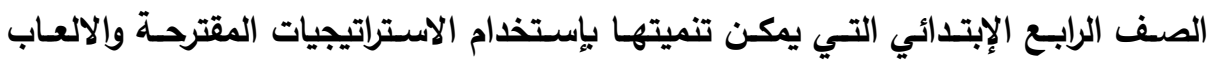

التعليمية الاكترونية ؟ قامت الباحثة بالاجراءات التالية:

1- إعداد بطاقة ملاحظة لقياس مهارات التحدث علي مجموعة الاطفال المختارة ورصد

النتائج.

r- ت تطبيق الاختبار المصور وبطاقـة الملاحظة علي مجموعـة من التلاميذ المختارة

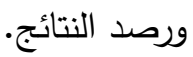

وللإجابة علي السؤال الرابع: ما الاستراتيجية المقترحة المناسبة القائمسة علي التعلم النشط

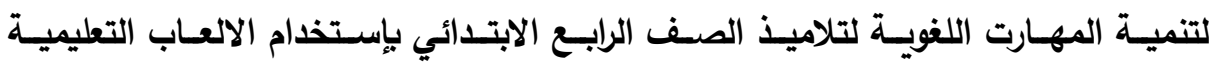
الالكترونية؟ قامت الباحثة بالإجراءات التالية:-

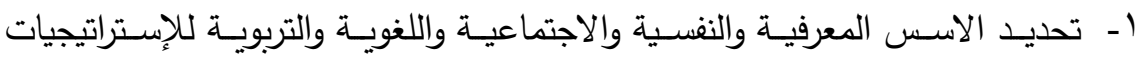

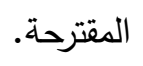

r- ت تحديد الانثطة المناسبة لعرض الانماط اللغوية.

r- تحديد الاجراءات المناسبة في ضوء الاستراتيجية المقترحة القائمة علي التعلم النشط. 
عـ - تحديد أساليب التقويم الثامل المناسبة لموضوع البحث.

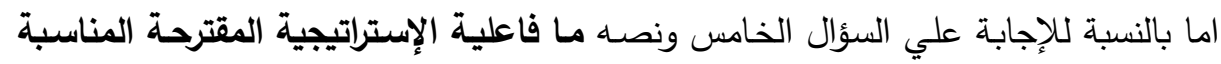

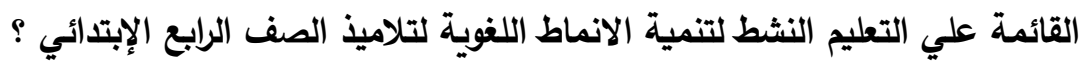
قامت الباحثة بالإجراءات التالية:

1- تطبيق الاختبار المصور وبطاقة الملاحظة تطبيقاً قلبياً علي المجموعة البحثية. r- التدريس وفق الاستراتيجية المقترحة بإستخدام الأنشطة البحثية. r- تطبيق الإختبار تطبيقاً بعدياً بلي المجموعة البحثية.

$$
\begin{aligned}
& \text { ع- ـ رصد النتائج وتقسيرها. } \\
& \text { 0ـ ـ معالجة البيانات وتفسيرها. } \\
& \text { T- تقديم التوصيات والمقترحات. }
\end{aligned}
$$

وتم استخدام معامل الفا كرونباخ علي عينـة من تلاميذ الصف التف الرابع الابتدائي

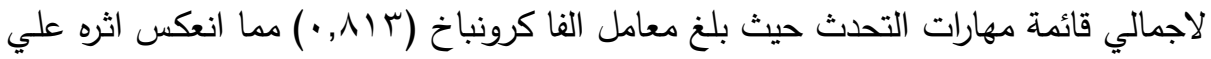

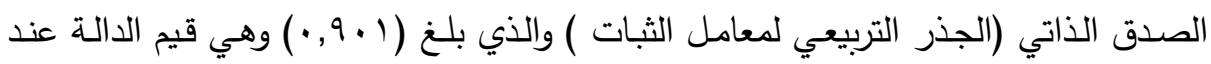
مستوي (0. . •) فأقل علي الدرجة الكلية مما يطمئن علي ثبات المقياس. واكدت قيم معامل الفا كرونباخ اعتمادية هذه المحاور بشكل كبير حيث تراوحت

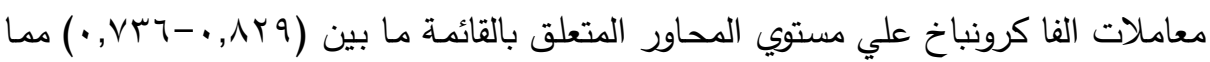

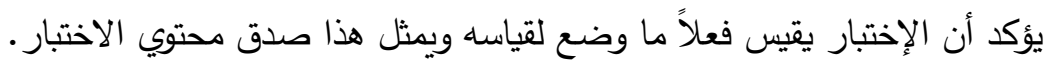

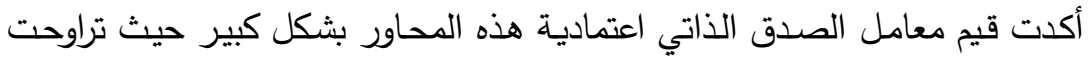

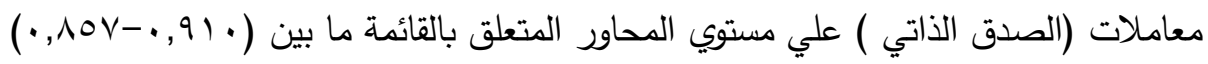

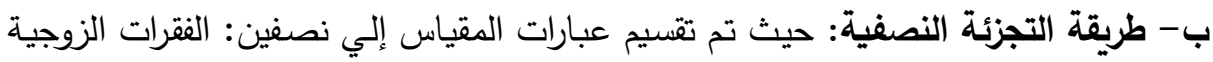

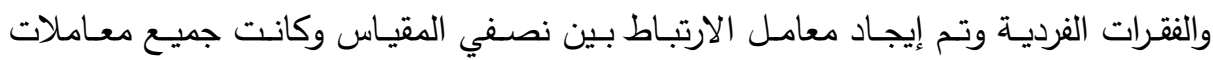

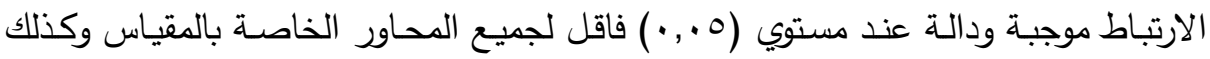
الدرجة الكلية كما يوضحه الجدول التالي: جدول( (1) يوضـح معامل الثبات والصدق والتجزئسة النصفية (قائهـة مهارة التحدث لتلاميذ المرحلة الإبتدائية) 
جدول يوضح إستخدام معامل الفا كرونباخ وسبيرمان براون

\begin{tabular}{|c|c|c|c|}
\hline 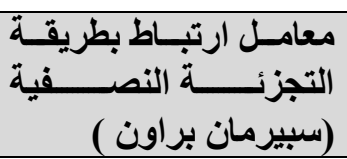 & معامل الصدق & معامـل ثرنبـات & المقياس \\
\hline$\cdot, V T V$ & $\cdot, 91$. & $\cdot, \wedge Y q$ & التحدث بوضو ح و ثقة \\
\hline$\cdot, 190$ & $\cdot, \wedge \circ \mathrm{V}$ & $\cdot, V T_{T}$ & النطق السليم \\
\hline$\cdot, \Lambda T V$ & $\cdot, \wedge 94$ & $\cdot, \vee \vee 9 \wedge$ & استخدام انماط لغوية \\
\hline$\cdot, \vee 99$ & $\cdot, 9 \cdot 1$ & $\cdot, \Lambda 1 \Gamma$ & 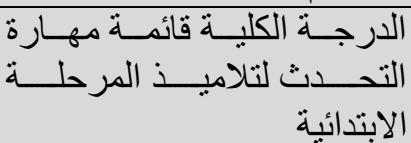 \\
\hline
\end{tabular}

ج - طريقة حساب الاتساق الداخلي:

بإستخدام طريقة الاتساق الداخلي علي عينـة من تلاميذ المرحلة الإبتدائية وذلك الكافي

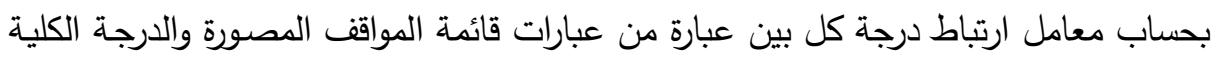

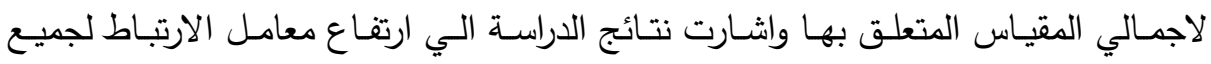

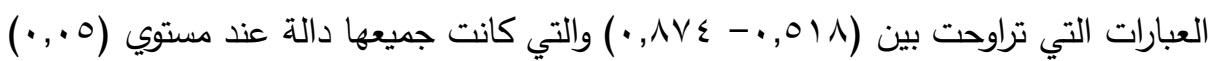

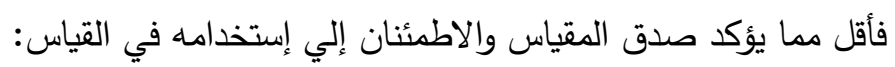
جدول (r) يوضح الاتساق الداخلي لإيجاد العلاقة بين كل عبارة من عبارات " قائمـة مهارة

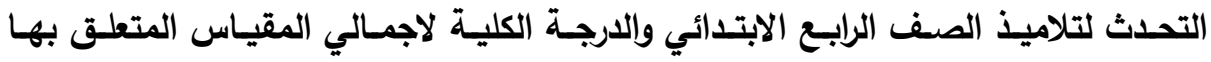

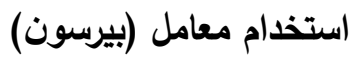

\begin{tabular}{|c|c|}
\hline معامل الارتباط (Y) & فقرات قائمة مهارات تحدث لتلاميذ الصف الرابع الإبتدائي \\
\hline$\cdot, \wedge \vee \leq$ & يتحدث بصوت واضح \\
\hline$\cdot, 77 \wedge$ & ينطق الكلمات نطقاً صحيحاً \\
\hline$\cdot, 7 \leqslant 0$ & يفرق بين التعريف و التنكير \\
\hline$\cdot, 71 \cdot$ & يستخدم اسماء الاشارة في اثناء الكلام \\
\hline$\cdot, 7 r 7$ & يعبر شفوياً عن الوب الاستفهام بطريقة صحيحة \\
\hline$\cdot, 047$ & يتفاعل مع الاخرين من خلال الكلمات \\
\hline$\cdot, \times 91$ & يربط كلامه ببعض \\
\hline • & يعبر عما يريد باستخدام الجملة الفعلية \\
\hline$\cdot, \vee \vee \leqslant$ & يستطيع ان يبدأ حوار مستخدماً اسلوب النداء. \\
\hline$\cdot, 7 V \cdot$ & يتحدث مع من هم في منل سنه بطلاقة \\
\hline$\cdot, 09 \mathrm{~V}$ & يستطيع ان يسال باستخدام بعض اساليب الاستفهام \\
\hline$\cdot, 0 T \leq$ & يستطيع ان يعبر عن الرفض باستخدام اسلوب النهي \\
\hline$\cdot, 77 \leq$ & يستطيع ان يدير حوار أ كاملاً \\
\hline$\cdot, 71 \cdot$ & ينطق الكلمات المنونه نطقاً صحيحاً \\
\hline
\end{tabular}




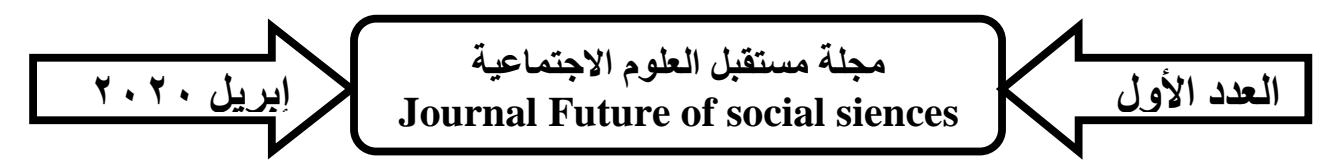

\begin{tabular}{|c|c|}
\hline معامل الارتباط (Y) & فقرات قائمة مهارات تعدث لتلاميذ الصف الرابع الإبتدائى \\
\hline$\cdot, V \cdot r$ & ان يذكر التلميذ معلومات عن نفسه و عائلته ب (أنا) \\
\hline., 011 & يسمي بعض اجز اء جسده بإستخدام اسم الاشارة \\
\hline
\end{tabular}

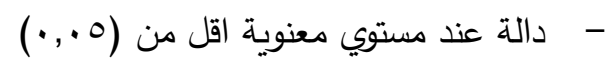

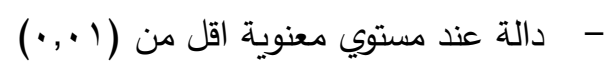

هـ - تحليل محتوي منهج اللغة العربية للصف الرابع الإبتدائي وذلك كالأتي:

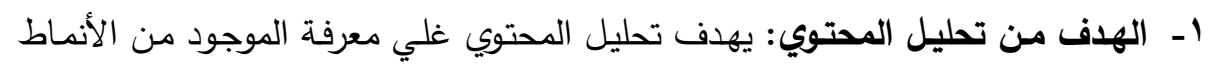
اللغوية في كتاب المدرسة للصف الاول من المرحلة الابتدائية حتي وان كانت موجودة

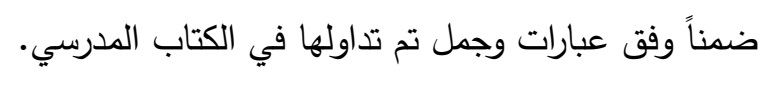
r- مصدر بناء بطاقة تحليل المحتوي:

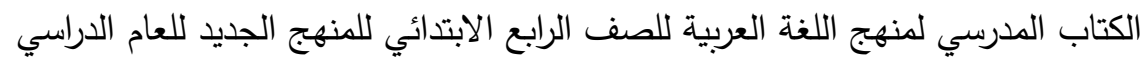

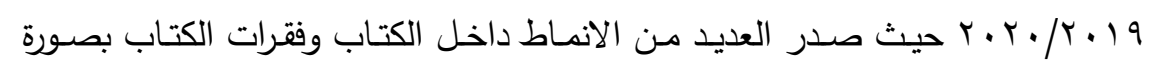
عرضية وقامت الباحثة في هذا البحث في توظيفها في صورة انثطة لتتمية استخدامها في الاداء الثفهي.

r- ربط المحتوي بالاهداف: يعتبر ربط المحتوي بالاهداف من أهم معايير اختيار المحتوي

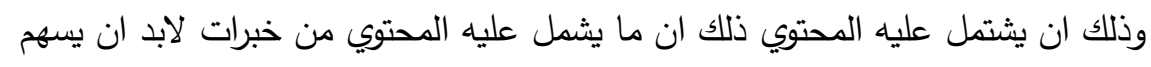

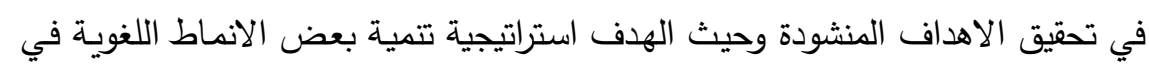
الاداء الثفهي باستخدام الالعاب التعليمية الالكترونية.

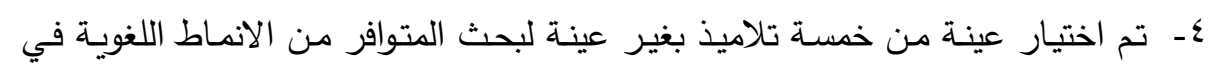

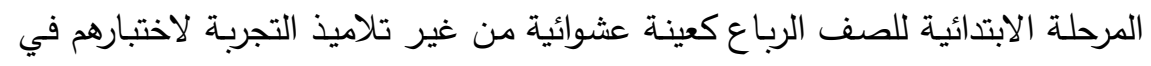
الانماط.

جدول (r) يوضح الانماط اللغوية في الاداء الثفهي للمرحلة الابتدائية للعينة العشوائية

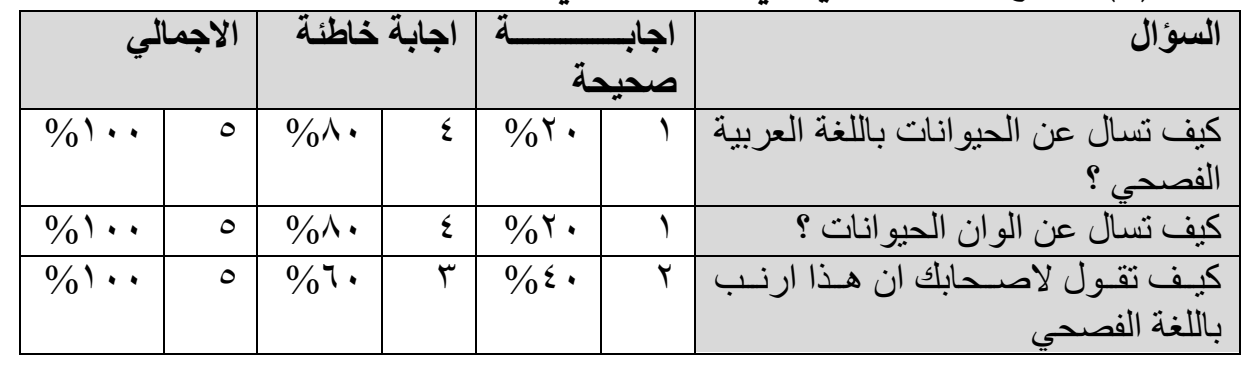
من الجدول السابق يتضح ما يلي: 


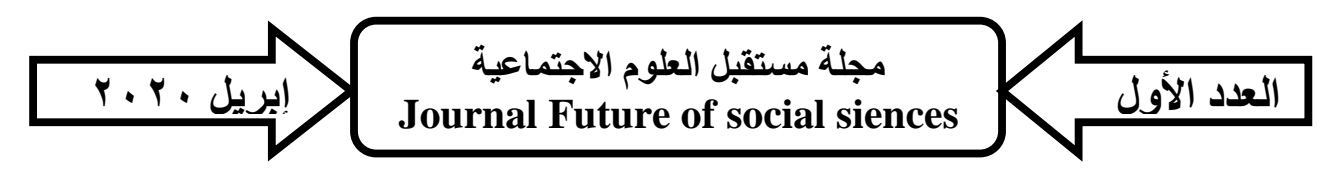

- ضعف وجود الانماط اللغوية فيالاداء الثفهي للتلاميذ في المرحلة الابتدائية. ثانياً: بناء الاستراتيجية المقترحة لتنمية الأنماط اللغويـة في الأداء الثفهي لمرحلة التعليم الابتدائي.

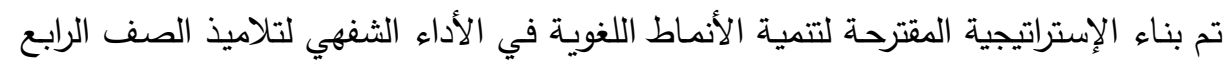

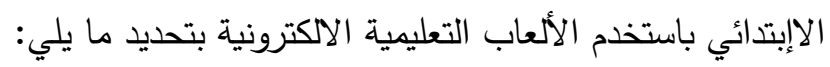
ا - أهداف الإستراتيجية المقترحة القائمة علي التعلم النشط. r- المحتوي المناسب للإستراتيجية المقترحة القائمة علي التعليم النشط. r- - طرق التدريس المناسبة للإستراتيجية المقترحة القائمة علي التعلم النشط. عـ - الانشطة المناسبة للإستراتيجية المقترحة القائمة علي التعليم النشط. 0ـ - طرق التقويم في الإسترتيجية المقترحة القائمة علي التعلم النشط. أهداف الإستراتيجية المقترحة القائمة علي التعلم النشط: تهاف الإستراتيجة المقترحة إلـي تنمية الإنماط اللغويـة في الأداء الشفهي لتلاميذ الصف

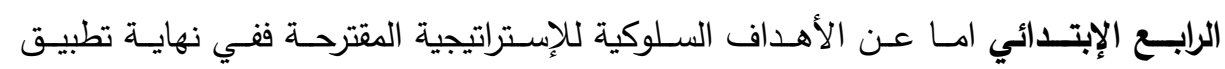
الإستراتيجية المقترحة يكون كل تلميذ من تلاميذ الصف الرابع الإبتدائي قادراً علي أن: - - يميز التذكير والتأنيث. - - ينادي بالياء في جملة كاملة. - يحذف (ال) التعريف. - ميقول جملة كاملة تبدأ بأنا لا، افعل. - يعبر عن الرفض بجملة كاملة بإستخدام أداة النهي لا. - - يردد جملة كاملة. - - يقول كلمة كاملة تبدأ بأنا لا، فعل. - - يضيف اسم أشارة مناسب مذكر / مؤنث. - ينطق الجمل والكلمات نطقاً صحيحاً. - - يتعرف شكل التتوين بأنواعه. - - يتعرف صوت التوين بأنواعه. - - ينطق ويرجح كلمات مختلفة منونة بإختلافها.

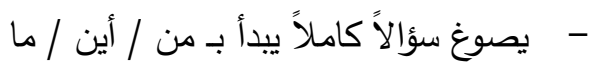




\section{r.r. إبريل}

\section{مجلة مستقبل العلوم الاجتماعية}

Journal Future of social siences

المحتوي المناسب للإستراتيجية المقترحة القائمة علي التعليم النشط

قامـت الباحثـة بإعداد المحتوي الـني يـدرس لتلاميذ الصـف الرابـع الإبتدائي مسن خـلال

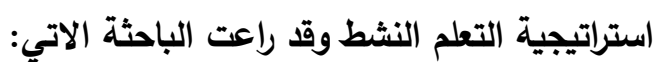
- - اختيار قصص مناسبة ومختلفة في مضامينها وأهدافها. - صياغة بعض الأسئلة المفتوحة والمقيدة للقصص المختارة قبل قراءتها وبعدها وحيث فيثاري تميل الباحثة لفكرة تتمية الحس النقدي للتلاميذ واجراء نقاش مفتوح في القاعة. - ان تكون القصص مناسبة الطول والفاظها سهلة وفكرتها واضحة وان تكون ملونـة وجذابة وصفحاتها كبيرة ويستطيع التلاميذ مشاهدتها بسهولة.

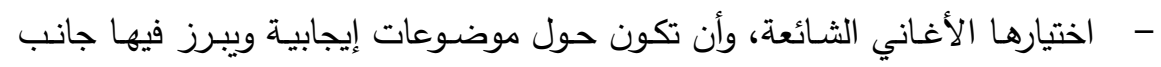
الخير وتضيف رصيد لغوياً للتلاميذ وذات إيقاع جذاب.

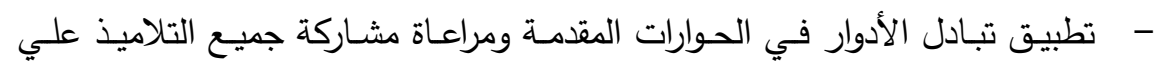

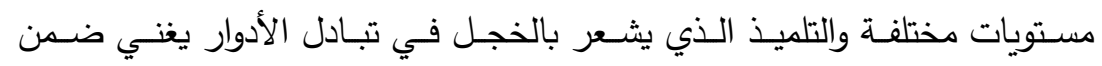

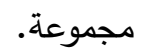
وجاء المحتوي علي النحو التالي: جدول ( ) يوضح تطبيق الأنماط من خلال الإستراتيجيات

\begin{tabular}{|c|c|c|}
\hline الدرس & النمط & 5 \\
\hline أغنية ناجي مؤدب & التنكير و التأنيث & 1 \\
\hline قصة حام & 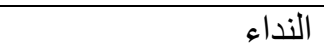 & $r$ \\
\hline أغنية عنيد في بيتي عصفور & الجملة الفعلية و الأسمية & $r$ \\
\hline اغنية نشيد صديقي & التعريف بالـ & $\varepsilon$ \\
\hline قصة انا أنسان & الجملة الأسمية (أنا) & 。 \\
\hline قصة حسام وسميرة & النهي بـــال & 7 \\
\hline أغنية الحواس الخمسة & أنا + فعل & $\bar{v}$ \\
\hline أغنية الحواس الخمسة & النفي ب لا + أفعل & $\wedge$ \\
\hline اغنية الف ارنب & أسماء الإشـارة & 9 \\
\hline اغنية كان عندي بغبغان & التنوين بالضم & 1. \\
\hline اغنية ضحي في الحديقة & التنوين بالكسر & 11 \\
\hline قصة الذئاب الثلاثة & الاستفهام بـــن & Tr \\
\hline هيا نتعلم & الإستفهام بـ ما & $1 \varepsilon$ \\
\hline قصة اسامة يسأل & الإاستفهام بــ أين & 10 \\
\hline أغنية بسم الله & أنا + فعل & 17 \\
\hline
\end{tabular}


الأنثطة التدريسية المناسبة للإِستراتيجية المقترحة القائمة علي التعلم النشط.

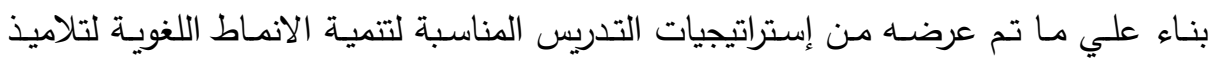
الصف الرابع الإبتدائي. فإن الباحثة قد مزجت بين الإستراتيجيات التدريسية في أثناء تتمية مهارات التحدث وبما يراعي الفروق الفردية للتلاميذ وفي ضوه الإستراتيجات التدريسية التي تم عرضها حيث تلتاول البحث

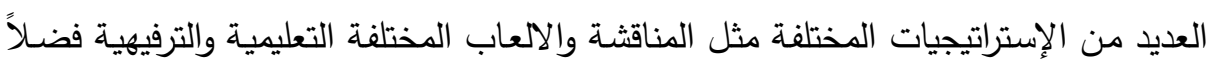

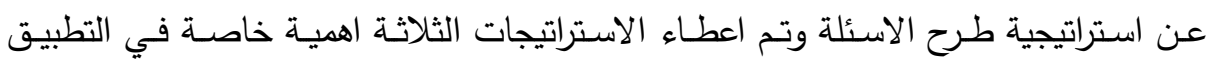
استراتيجية القصص - الأغاني - تبادل الأدوار.

ويمكن ان يوضح الجدول التالي دور كل المعلمة والتلاميبذ في الإستراتيجية المقترحة

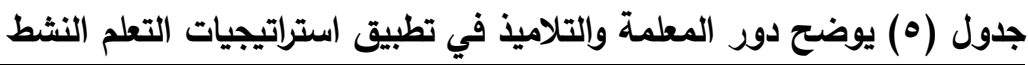

\begin{tabular}{|c|c|c|}
\hline دور التلاميذ بمساعدة المعلمة & دور المعلمة & ק \\
\hline الإستماع بحرص ومشاهدة الصور & تحديد القصص والأغاني المناسبة & 1 \\
\hline الإستجابة لأسئلة المعلمة. & اعداد بدايات مشوقة لكل قصة وأغنية & $r$ \\
\hline تمثيل بعض المشـاهد مـن القصـص & تلكليـف التلاميـذ بتمثيـل بعض الادوار فـي & r \\
\hline يعبر التلاميذ عن بعضهم ما يعجبهم. & 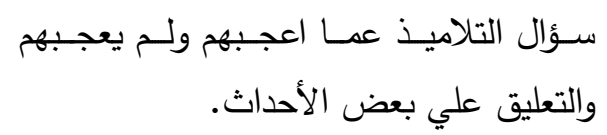 & $\varepsilon$ \\
\hline تتفيذ الأنشطة بمشاركة المعلمة & المساعدة والتوجيه في تتفيذ بعض الأنشطة & 0 \\
\hline في أمثلة مشابهة. & تالتي تتناوله وان تكون لغتوب النمط اللغوي بالأمثلة الثـائعة واضحة ومباشرة & 7 \\
\hline
\end{tabular}

○ـ الأنشطة المناسبة للإستراتيجية المقترحة القائمة علي التعلم النشط: -

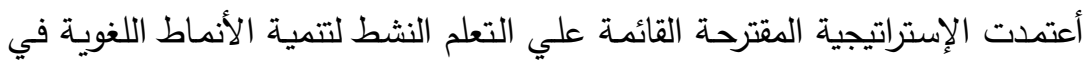

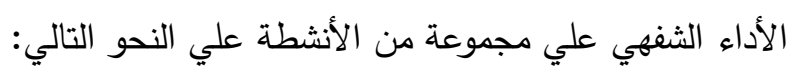
- - يستمع التلاميذ للأغاني المعروضة من عليهم وحفظها قدر المستطاع والغناء والترديد. - - يتامل التلاميذ الصور المتضمنة في القصص المختارة. 


\section{r.r. إبريل}

- - تبرز المعلمة مجموعة من الصور التي عن طريقها سيكون التدريب علي الانماط اللغوية من خلالها ومن خلال الالعاب التعليمية الآكترونية.

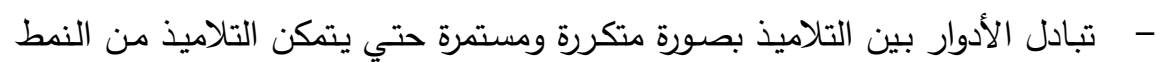

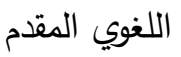
؟- طرق التقويم المناسبة للإستراتيجية المقترحة القائمة علي التعلم النشط لتتمية الأنماط

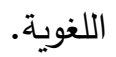
يتم التقويم في الإستراتيجة المقترحة من خلال مايلي:

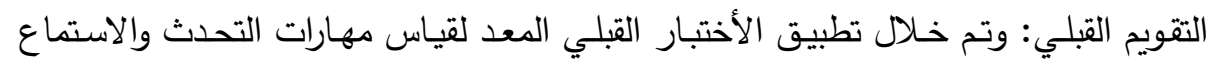

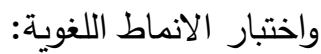
يتم التقويم في الإستراتيجية المقترحة من خلال ما يلي:

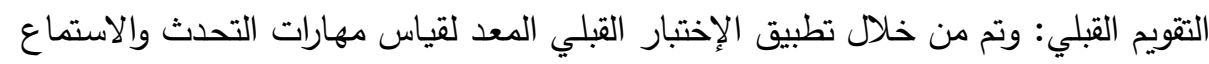
واختبار الانماط اللغوية ليد التلاميذ في المرحلة الإبتدائية.

تفسير النتائج ومناقشتها:

توصل البحث الحالي إلي فاعلية الإستراتيحية المقترحة القائمة علي التعلم النشط في

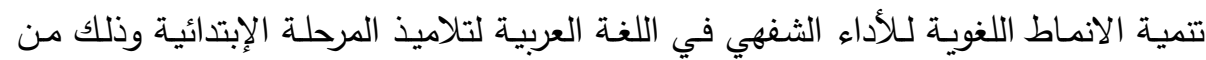

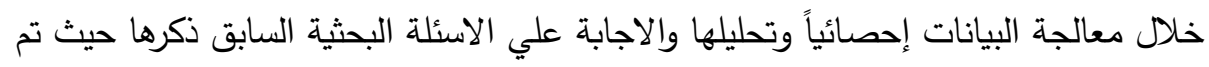

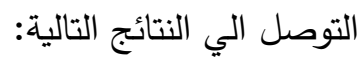
1- يوجد فرق إحصائياً بين متوسطي درجات المجموعة التجريبية في القياسين القبلي

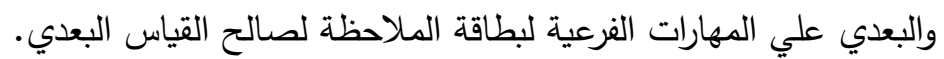
r- يوجد فرق دال احصائيا بين متوسطي درجات مجموعة البحث في القياسين القبلي والبعدي علي الدرجة الكلية لبطاقة الملاحظة لصالح القياس البعدي. - توصيات البحث: تأسيسا علي نتائج البحث، فإن الباحثة توصي بما يلي:

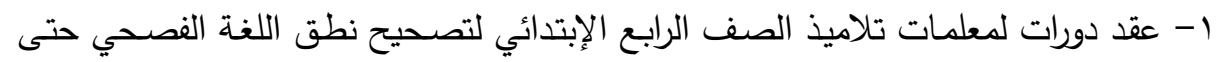
يستطعن التحدث منع الأطفال بطريقة سليمة أثناء ممارسة الأنثطة.

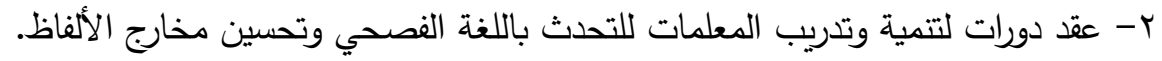


r- عقد ندوات تدريبية تتافسية للتحدث بالفصحي تحت إثراف خبراء باللغة العربية لتثجيع المعلمات للتحدث بالفصحي.

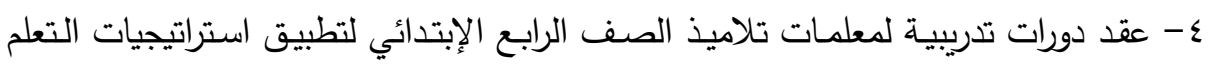
النشط لتعليم اللغة العربية لتلاميذ الصف الرابع الإبتدائي. ه- تثجيع المعلمات علي استخدام الاستراتيجيات المختلفة الخاصـة بتحفيز التفكير وإثارة الأسئلة. 1- أن ينوع مصممو المناهج الدراسية أساليب التقويم التي تستخدها معلمات الصف الرابع الإبتدائي وكذلك العلم علي تكامل مناهجها.

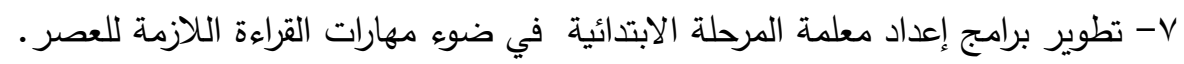

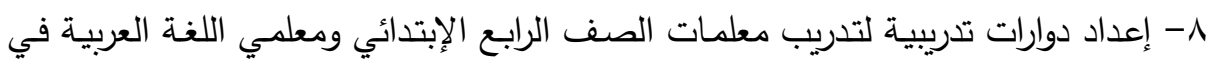

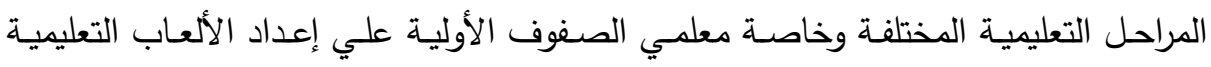
وطرق إستخدامها في التدريس.

9- إعـداد ورش تعليميـة ودورات تدريبيـة لتدريب المعلمـات علـي إنتـاج الوسـائل التعليميـة واستخدامها في تدريس المواد. • ا- أن يتضمن منهج اللغة العربية ألعابا تعليمية ألغازا لمختلف الصفوف التعليمية خاصـة

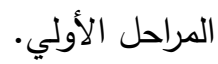
1 1) ضرورة تضمين برامج إعداد المعلمين بكليات التربية بنماذج ونظريات صميم الألعاب الاب بحيث تهيئ الطالبات المعلمات لاستخدامها في فترة التدريب الميداني مستقبلا. r ا - ضرورة توظيف الألعاب التعليمية في تدريس المباحث الدراسية بثكل عام، ومناهج

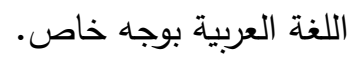

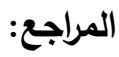
النعيمي، أحمد محمد حسن، 19 ب ( ) (فاعلية برنامج قائم على البنائية الاجتماعية في تتمية

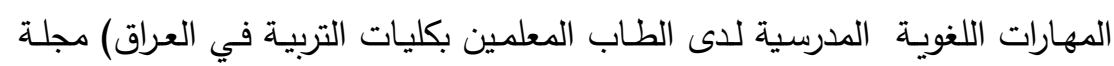

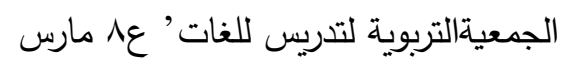

شحاته،حسن سيد (2018)وأخرون (المهارات اللغوية الوظيفية لللأزمة للتلاميذ المعاقين

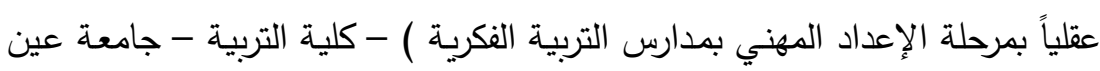
شمس 


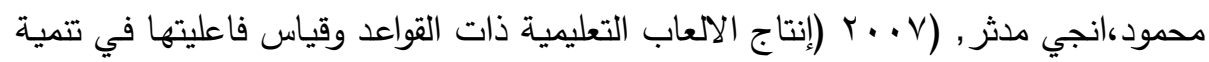

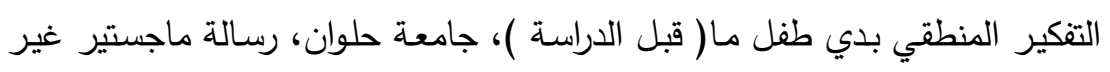

$$
\text { منشورة، التعبرة }
$$

عبدالله, بن محمد سليما (2010) العليط مستوى اللغوي الثففهي لتلاميذ الصف السـادس

$$
\text { الابتدائي في المهارات المحتارة. }
$$

عويضة،جميل، 2001الأنماط اللغوية مفهومها، وأهدافها، وأساليب تدريسها والتدريب عليها".

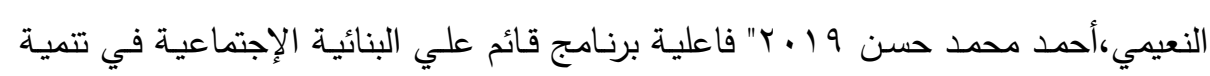

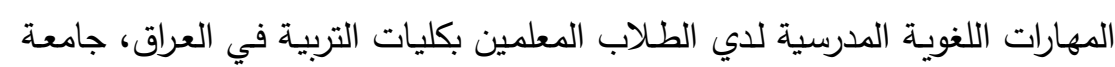

$$
\text { عين شمس، رسالة دكتوراه }
$$

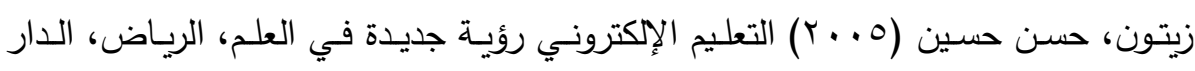

$$
\text { الصولتية. }
$$

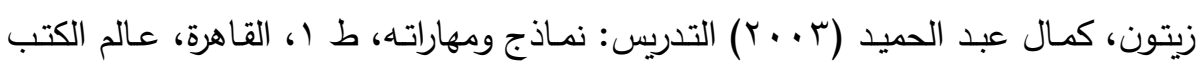
اللبنانية.

زين الدين، محمد (· ( • (Y) فاعلية برنامج تدريب مقترح في تتمية مهارات إستخدام وسائط

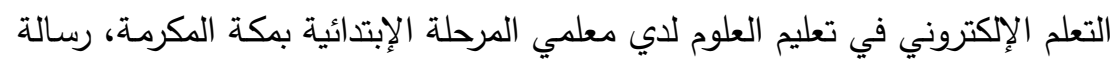

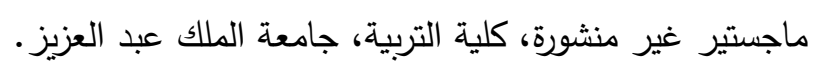

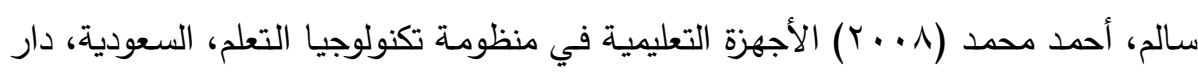

$$
\text { الزهراء للنشر والتوزيع. }
$$

السعيد، رضا (T . †) تطوير المناهج الدراسية تطبيقات ونماذج القاهرة، دار الفكر العربي.

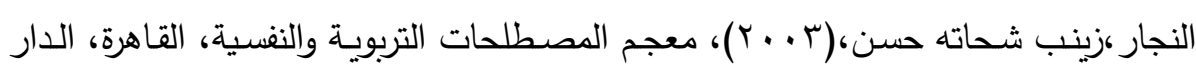

المصرية اللبنانية.

مقصود، أماني، واخرون (10 · ب) مقياس دافعية الإنجاز للاطفال المراهقين، القاهرة، مكتبة الإنجلو المصرية.

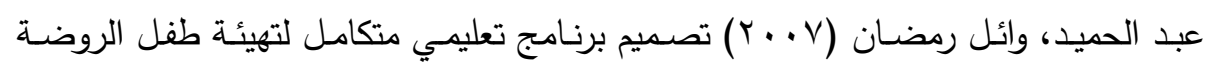

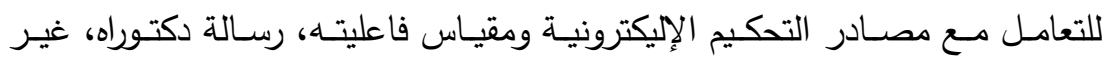
منشورة، كلية التربية، جامعة حلوان. 


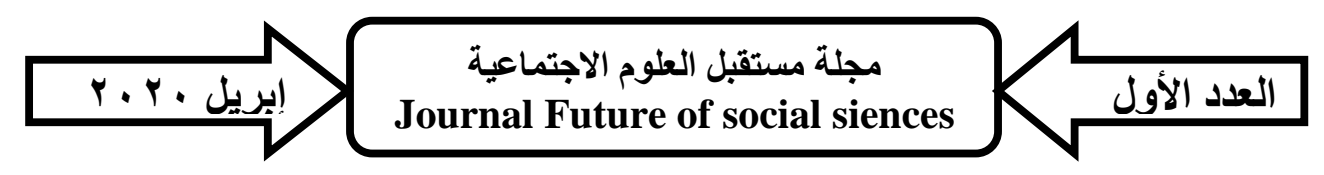

عطيفي، زينب محمود واخرون(؟ ا ـ r) فاعلية إستخدام الألعاب التعليمية الإليكترونية لتقديم المفاهيم الهندسية لأطفال ما قبل المدرسة في تتمية بعض مهارات التفكير الإبداعي

$$
\text { لديهم، مجلة الدراسات في المناهج وطرق التدريس ع ه ه . ب. }
$$

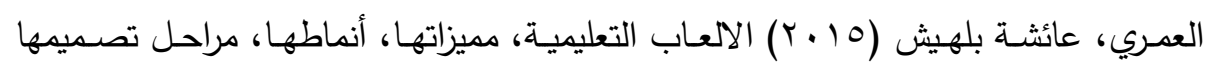

http / learning - oth / index. php? Option.com متاح علي الرابط ميري

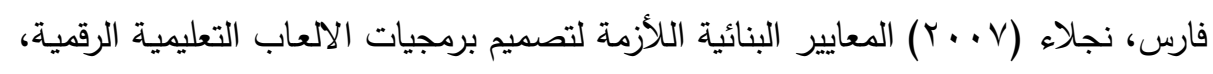

مجلة البحث في التربية وعلم النفس، العدد Y، مجلد ا (Y، كلية التربية، جامعة المنيا.

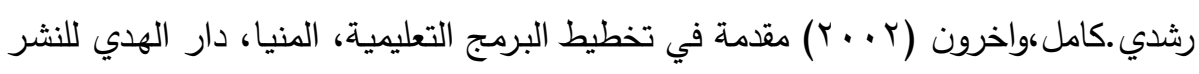
والتوزيع.

الحيلة، محمد محمود (V . . . r)، تكنولوجيا التعليم بين النظريـة والتطبيق، الاردن، المسيرة للنشر والتوزيع والطباعة. 


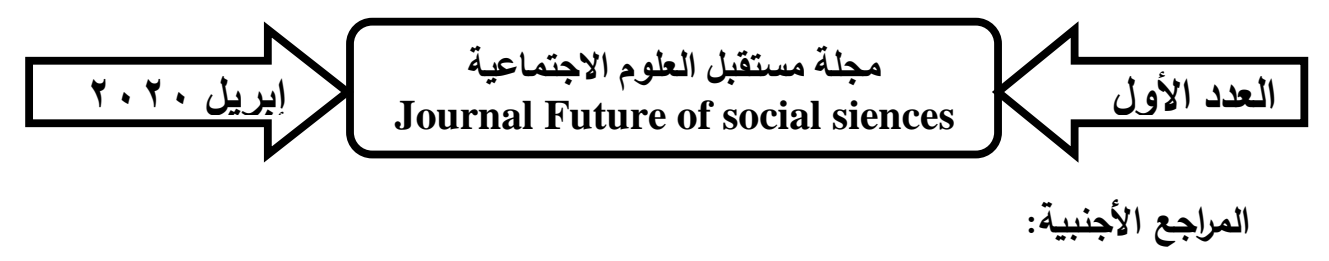

Simon. kucher\& partners،2014. strategy\&marketing consultants, Villette (2016) do young children grasp the inverse relationship between addition and subtraction? cognitive Development, 17(34).

Simon.R.(2014). teaching arithmetic to students with learning duslitity: A- unique approach Dissertation Absracts international,42(04)

Lai, m: baroody, Ap Johnson, a (2008) fostering Taiwanese preschoolers understanding of the addition subtraction inverse principle cognitive development‘23(1) 